\title{
Intercâmbio de germoplasma de hortícolas: regulamentação e procedimentos
}

\author{
DALMO C. GIACOMETTI \\ Pesquisador do Centro Nacional de Pesquisa de Recursos Genéticos e Biotecnologia \\ CENARGEN/EMBRAPA \\ (In memorian)
}

\section{PREFÁCIO}

O enriquecimento da variabilidade genética de determinada cultura se realiza através de introduções de germoplasma de fontes externas e de coleta de germoplasma autóctone.

As introduções constituem a transferência ordenada e sistemática de germoplasma para o País com objetivos previamente determinados. A ordenação se refere à obediência às exigências de leis e regulamentação, tanto por parte do país doador quanto do receptor e sistemática para que as introduções sejam contínuas e freqüentes, principalmente quando feitas para atender à necessidade de programas de melhoramento genético e pesquisa agrícola correlata.

As introduções, através de coleta, constituem importante componente do enriquecimento de germoplasma e visam resgatar materiais cultivados, principalmente variedades locais ou obsoletas e espécies silvestres relacionadas ou não às espécies cultivadas.

O germoplasma introduzido é conservado em repositórios de genes denominados bancos de germoplasma ou coleções ativas. Modernos sistemas de conservação incluem: a) conservação a longo prazo, em forma de sementes ortodoxas que resistem à dissecação a 6-8\%, em câmaras com temperatura de -18 a $-20^{\circ} \mathrm{C}$ e b) coleções in vivo, e criopreservação em nitrogênio líquido à temperatura de $-196^{\circ} \mathrm{C}$.

A maior parte das espécies de plantas ornamentais é conservada em coleções in vivo, porém elas se adaptam satisfatoriamente in vitro cujas condições fitossanitárias são ideais.

\section{CATEGORIAS DE GERMOPLASMA}

- Parentes silvestres: são as espécies silvestres aparentadas com as espécies cultivadas, ainda ocorrendo em seu habitat. São espécies do mesmo gênero ou de gêneros afins. Exemplos: Rosa spp., Iris spp., Rododendron spp., e diversas espécies de orquídeas;

- Espécies silvestres: espécies com potencial para domesticação. Exemplos: arbustos floríferos do cerrado;

- Cultivares primitivos: variedades locais desenvolvidas em sistema de agricultura primitiva, selecionadas através de várias gerações pelo próprio agricultor;

- Cultivares obsoletos: variedades obtidas através de melhoramento genético, porém superadas; encontradas em ban- 
cos de germoplasma, raramente entre produtores;

- Cultivares modernos: variedades melhoradas de alto rendimento e de qualidade superior;

- Linhas avançadas para melhoramento genético e mutantes: são linhas obtidas pelo melhorista (pre-breeding lines) para cruzamentos em melhoramento genético e mutações induzidas ou naturais, porém, selecionadas;

- Microorganismos: espécies e linhagens de fungos, bactérias e vírus usados em controle biológico, indústria de fermentação, fixação de nitrogênio no solo e engenharia genética;

- DNA: clonado e conservado em bancos genômicos.

\section{ESTRATÉGIAS DE INTRODUÇÃO}

A doação de germoplasma por fontes do exterior padece de uma série de restrições que freqüentemente dificultam projetos de melhoramento genético. Restrições essas feitas, principalmente, por parte de certos países extremamente possessivos, sendo que alguns possuem lei restritiva como é o caso da pimenta-do-reino para a Índia.

Quando determinado país não possui restrições legais, como é o caso dos Estados Unidos, o intercâmbio é livre nas duas direções, entretanto têm sido freqüentes as exigências de protocolos bilaterais que garantam o intercâmbio das partes signatárias quando uma ou as duas partes tem restrições legais.

As leis de proteção dos direitos do melhorista e de patentes de cultivares têm sido acusadas de criar dificuldades no intercâmbio de germoplasma, entretanto, tanto a lei americana quanto a da União dos Produtores de Novas Variedades de Plantas (UPOV) da Europa, estabelecem que os materiais protegidos pelos dois sistemas sejam franqueados ao intercâmbio para uso como germoplasma. A diferença está em que no caso do direito do melhorista, o novo cultivar obtido com germoplasma protegido pode ser registrado e protegido e não carece da permissão do detentor do direito ao passo que, no caso de patente, o novo cultivar obtido com germoplasma patenteado somente poderá ser patenteado com permissão do detentor da patente anterior (MAST, 1986). Quando se introduzem materiais protegidos, assina-se um termo de compromisso assegurando que os mesmos serão utilizados exclusivamente para pesquisa. A validade internacional, entretanto, é discutível para países receptores que não possuem legislação que reconheça os direitos do melhorista ou de patentes para cultivares.

As fontes doadoras de germoplasma no exterior são as seguintes:

- Instituições governamentais: na maioria contituídos de instituições de pesquisa, freqüentemente universidades com bancos de germoplasma e coleções de trabalho;

- Centros internacionais de pesquisa agrícola: criados e mantidos pelo "Consulative Group on International Agricultural Research", manejam germoplasma de culturas alimentícias prioritárias;

- Companhias privadas: contatar preferivelmente o melhorista da espécie de interesse; quando se tratar de material protegido, obedecer às exigências.

As solicitações no exterior somente terão êxito quando obedecerem a certos requisitos, tais como: solicitar preferivelmente ao cientista que maneja o material; 
nunca solicitar grande número de acessos; sempre escrever na língua do doador; mencionar a finalidade; indicar as exigências legais do país receptor para facilitar o desembaraço pela alfândega nos locais de entrada (aeroportos, portos e estradas internacionais). O certificado fitossanitário é absolutamente necessário, mesmo quando se introduz pessoalmente. Declaração adicional no Certificado afirmando que o material NÃO TEM VALOR COMERCIAL e constitui DOAÇÃO PARA PESQUISA, evita problemas com a alfândega, principalmente quando se trata de material volumoso.

\section{LEGISLAÇÃO E PROCEDIMENTOS}

Desde 1953, opera uma Convenção Internacional de Proteção Fitossanitária que consiste num acordo intergovernamental aprovado pela $6^{\mathbf{a}}$ Conferência da FAO, em dezembro de 1951. Essa convenção prevê o estabelecimento de Comitês Regionais de Proteção Fitossanitária que atuam com o suporte da FAO.

Entre as várias providências estabelecidas pela convenção, destaca-se a exigência do Certificado Fitossanitário Internacional como documento indispensável ao trânsito e liberação do material nos pontos de saída e de entrada, respectivamente, no país doador e país receptor. As informações do certificado obedecem às exigências específicas da regulamentação de cada país, com relação a pragas e doenças.

De acordo com KAHN (1977), os regulamentos de quarenta dos países tem as seguintes características em comum:

- Proibição específica;

- Exceção à proibição para fins científicos;

- Exigências de permissão de importação;

- Exigência de certificado fitossanitário e/ ou certificado de origem;

- Estipulam inspeção na chegada;

- Prescrevem tratamento na chegada para eliminar riscos;

- Prescrevem quarentena, quarentena de pós-entrada e outras medidas de segurança.

As regulamentações nacionais para a introdução de plantas, visam reduzir os riscos de introdução de patógenos, insetos, nematóides e ácaros, principalmente aqueles que não ocorrem no país.

Segundo KHAN (1977), os riscos serão reduzidos se os regulamentos levarem em consideração as seguintes exigências:

- Preferivelmente, deve-se introduzir sementes em vez de material vegetativo, a não ser que se requeira material clonado;

- Para material clonado, deve-se preferir estacas não enraizadas;

- Material lenhoso não deve exceder dois anos de idade;

- Encomenda de material clonado deve ser pequena, limitada a poucos tubérculos, bulbos ou estacas;

- O material deve ser livre de terra. A importação original é incinerada, uma vez garantida a planta filha sadia;

- Se as exigências da quarentena prescrevem que o material clonado seja indexado para vírus, somente se liberará material indexado;

- Quando o material apresenta alto risco de organismos transmitidos por sementes, o original deve ser tratado e plantado para produção de sementes sadias;

- Para o material que de alto risco, quer seja em forma de sementes ou vegetativa, libera-se somente a parte que passou pela quarentena e a restante é destruída.

O risco de patógenos e pragas associados ao intercâmbio de germoplasma pode ser minimizado através de regula. 
mentos que estabeleçam a seguinte ordem decrescente, de acordo com a categoria do risco (KHAN, 1977):

1. Proibido: o risco é tão grande que as medidas de segurança são inadequadas, portanto, a importação é proibida mesmo por serviços governamentais;

2. Quarentena de pós-entrada: o risco é alto, entretanto, a passagem através de rigoroso serviço oficial de quarentena pode oferecer adequada segurança;

3. Restrito: embora a permissão seja exigida, ela pode estipular certas condições de entrada, as plantas estarão sujeitas a inspeções e tratamentos específicos na permissão. De toda maneira, estarão sujeitas à inspeção na chegada. Exemplo: para rosa procedente de países onde ocorra a Erwinia amylovora em maçã e pêra, a permissão no Brasil estabelece que o Certificado Fitossanitário declare que o material está livre deste patógeno.

4. Não restrito: os regulamentos não estabelecem restrições e não há necessidade de autorização. Infelizmente, a introdução de germoplasma de plantas ornamentais no Brasil não tem merecido a devida atenção das autoridades fitossanitárias nacionais e, assim as importações têm sido livres, o que tem causado problemas sérios, como "ferrugem" do gladíolo.

\section{LEGISLAÇÃO BRASILEIRA}

O Decreto Presidencial $n^{2} 24.114$ de 12 de abril de 1924 aprova o Regulamento de Defesa Sanitária Vegetal. O Decreto é composto de 10 capítulos e 143 artigos.

Convém ressaltar que vinte anos antes da implementação da Convenção Inter- nacional de Proteção Fitossanitária, o Brasil, graças à dedicação e à competência dos técnicos da defesa fitossanitária do Ministério da Agricultura, promoveu a assinatura desse Decreto cujas disposições para a introdução, fiscalização e penalidade para infrações já eram razoavelmente satisfatórias, entretanto, estabelecia facilidade para fins experimentais e científicos desde que se obedecesse às exigências.

Durante os 47 anos de vigência deste decreto, foram assinadas 47 Portarias Complementares com a finalidade de atualizar exigências decorrentes de doenças e pragas que ainda não ocorrem no Brasil, mas que podem ser introduzidas através de germoplasma ou sementes comerciais.

Este decreto foi também alterado por dois decretos, um em 1943 e outro em 1961 que, respectivamente, tratam de permissão para movimento interno de plantas vivas e da validade da certificação de desinfecção ou expurgo de grãos armazenados.

Atualmente, as Delegacias Federais de Agricultura, ligadas à Secretaria Geral do Ministério da Agricultura, junto ao Serviço de Desembaraço Vegetal nas alfândegas - este ligado à Secretaria da Defesa Sanitária Vegetal (SDSV) através do delegado para cada estado e atuando nos aeroportos, postos marítimos e fluviais e fronteiras secas, são responsáveis pela fiscalização da entrada de material vegetal e animal no país.

Para que o germoplasma vegetal entre regularmente no país, é indispensável obedecer os seguintes procedimentos exigidos por diversas portarias e seguidos pela SDSV ${ }^{1}$.

\footnotetext{
${ }^{1}$ No presente, para fins de pesquisa científica, vigora a Portaria $n^{2} 148$, de 15 de junho de 1992 que normatiza os procedimentos de intercâmbio de vegetais e solo.

Em São Paulo, o Instituto Agronômico vem efetuando introduções e quarentena de plantas, em estreito relacionamento com o CENARGEN e a DIFARA/SP (VEIGA et al., 1992) e também a COPERSUCAR (SANGUINO, 1988).
} 


\section{IMPORTAÇÃO PROIBIDA}

A. Plantas ou partes de plantas: a introdução deste material é permitida para fins de pesquisa oficial, mediante prévio Ato Autorizado do MA, e cuja solicitação é encaminhada à SDSV. Culturas proibidas: citrus, café, algodão, soja, banana, feijão, seringueira, cana-de-açúcar, sorgo, cacau e milho.

\section{B. 1. Terra, terriço e solo.}

2. Culturas de bactérias, vírus e fungos, cogumelos, insetos úteis ou benéficos, ácaros e plantas daninhas.

\section{RESTRIÇÃO CONDICIONAL}

Não há necessidade de autorização do Ministério da Agricultura, mas o Certificado Fitossanitário deve incluir declaração adicional, no caso de doenças específicas, conforme exigências da SDSV. Culturas: maçã, pêra e marmelo (declaração de que o material está livre de Erwinia amylovora e Nectria galligena), oliveira, batata e alfafa.

\section{MATERIAL NÃO PROIBIDO}

Somente será exigido o "Certificado Fitossanitário" emitido pelo órgão oficial do país de origem. O solicitante, consciente da necessidade de se obedecer a estes procedimentos, deve instruir devidamente o doador, porém, solicitará sempre o Certificado Fitossanitário.

A EMBRAPA, por decisão da diretoria, determinou que todas as instruções de germoplasma destinadas ao "Sistema Cooperativo de Pesquisa Agropecuária" fossem realizadas através do CENARGEN, por Brasília, justamente na expectativa de que o centro desenvolvesse um mecanismo dinâmico, seguro e efetivo de solicitar, in- troduzir, inspecionar, tratar e quarentenar, quando necessário, e liberar o material.

A fim de agilizar o processo introdutório, o centro celebrou em 1977 convênio com a SDSV. Através deste convênio, a SDSV tem cooperado efetivamente em processos de autorização para introdução de material que eventualmente não tenha obedecido cuidados fitossanitários para liberação.

A equipe de inspeção conta com especialistas em bacteriologia, micologia, nematologia, entomologia e virologia. A cultura de tecido e a termoterapia eventualmente são utilizadas para materiais infectados por vírus e nematóides sistêmicos.

$O$ centro mantém excelente relacionamento com a Delegacia Federal de Agricultura do Distrito Federal que destina um de seus técnicos para colaborar diretamente com a Área de Introdução e Intercâmbio de Germoplasma.

\section{RELAÇÃO RISCO/SEGURANÇA NA INTRODUÇÃO DE GERMOPLASMA}

A introdução de germoplasma está sujeita a riscos, mesmo que sejam obedecidas as exigências legais e que o material seja acompanhado do Certificado Fitossanitário. Por isso, as inspeções cuidadosas, realizadas por equipes especializadas de entomologistas, micologistas, nematologistas, bacteriologistas e virologistas, tornam-se indispensáveis em um sistema ordenado de introdução como aqueles em execução pelo CENARGEN, por onde passam anualmente mais de dez mil acessos desde 1976.

Uma vez realizadas as inspeções, que podem durar até cinco meses, e verificada a ausência de parasitas, já se tem condições de liberar o material ou decidir sobre as eventuais técnicas quarentenárias. Se houver inspeção nesta fase, o risco será reduzido para cerca de $30-50 \%$. 
A quarentena, que envolve tratamentos químicos ou técnicas de cultura de tecidos, pode durar de 6 a 24 meses, pois, no caso de virose, exige indexação do material tratado na fase final.

Nessas condições, pode-se reduzir ao máximo o risco e levar a segurança à uma situação que permita a liberação do material.

A representação gráfica da relação hipotética entre o risco e a segurança após a introdução, que prevê a inspeção, tratamento e quarentena, visando a liberação do material, foi estudada pela pesquisadora Célia Maria T. Cordeiro da Área de Informática e Biometria do CENARGEN, que propõe a Figura 1, onde se verifica que a ausência de quarentena implica em 100\% de risco e $0 \%$ de segurança e que segurança cresce a uma taxa crescente durante um a dois anos quando se aplicam todas as técnicas requeridas para quarentena pós-entrada. Quando se trata de material de propagação vegetativa, tais como: bulbos, tubérculos, rizomas, estacas e mudas, após a indexação, dependendo do patógeno encontrado, os propágulos são levados para o quarentenário e plantados em solo esterilizado. Quando se trata de borbulhas, enxerta-se em porta-enxertos sadios e quando se trata de estacas são postas a enraizar em solo esterilizado (GIACOMETTI, 1988).

\section{INTERCÂMBIODEGERMOPLASMAINVITRO}

Técnicas para o intercâmbio de germoplasma in vitro já bem desenvolvidas constituem medida adicional para aumentar a segurança e diminuir os riscos. Atual-

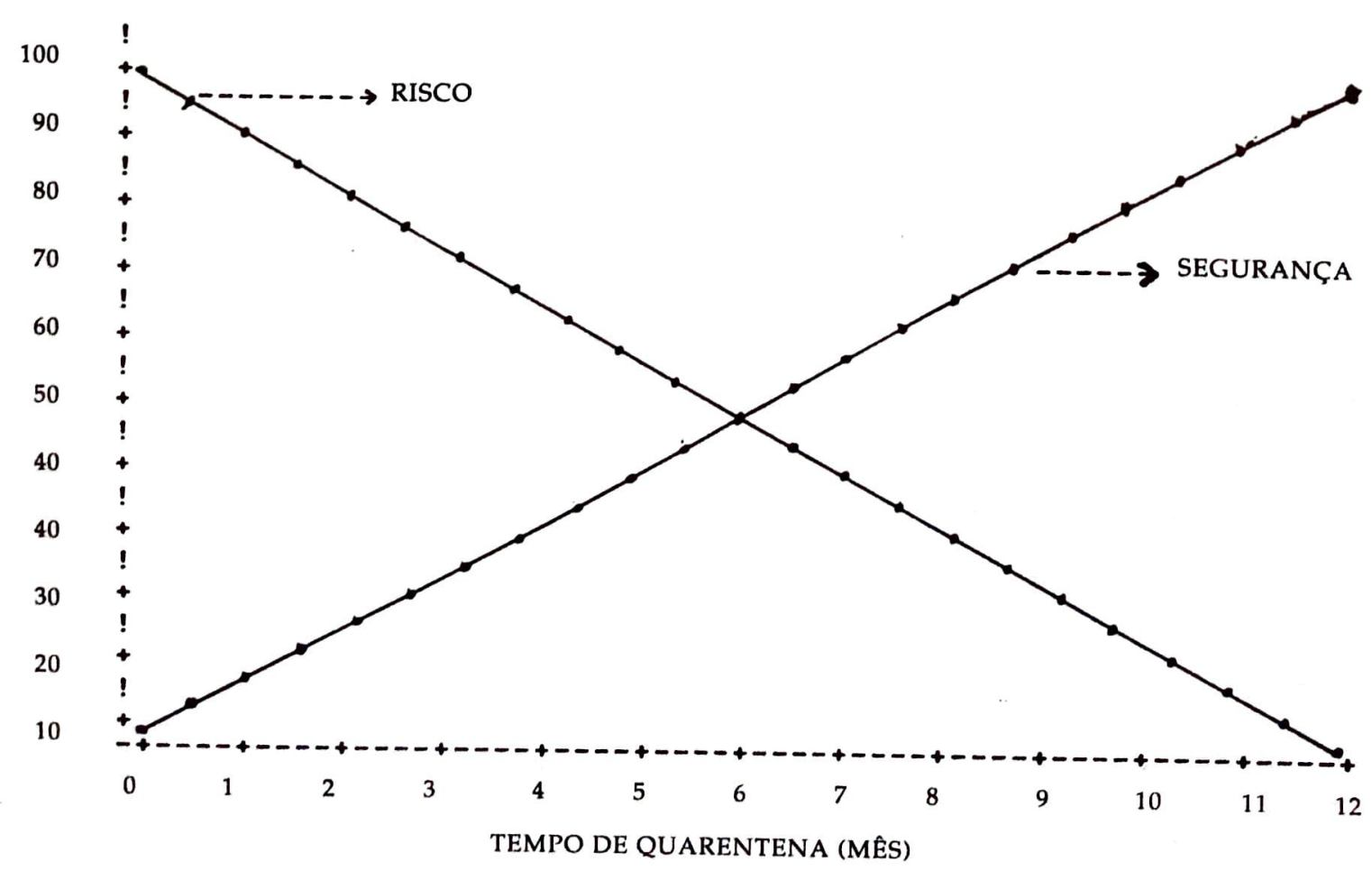

Figura 1. Relação hipotética entre o tempo de quarentena de germoplasma, a freqüência do risco e da segurança antes da liberação 
mente, essas técnicas são amplamente utilizadas para intercâmbio de banana, batata, batata-doce, cará, cravo, crisântemo, inhame, orquídea e rosa.

Os materiais micropropagados e despachados in vitro são obtidos de plantas básicas, previamente indexadas e livres de vírus, bactérias, fungos, nematóides, ácaros e insetos e mantidas in vitro, portanto, pode-se assegurar o bom estado sanitário do material recebido.

O problema do intercâmbio in vitro está em dominar a técnica de micropropagação e assegurar a sobrevivência das plantas, tanto durante o transporte, quando se requer embalagem especial, como no manejo do material recebido.

Para despachar germoplasma in vitro, DAMIANO (1986) recomenda tubos pequenos, seguramente fechados, com meio de cultura sólido para se evitarem distúrbios físicos. Os tubos são embalados com material antitérmico, preferivelmente caixas de isopor. Para se despachar plantas enraizadas, recomendam-se sacos plásticos esterilizados, devendo-se evitar excesso de umidade interior.

No caso de o país solicitante não possuir condições para manejar o germoplasma in vitro, adota-se o sistema de enviar as mudas enraizadas, porém, inicialmente micropropagadas in vitro e em seguida cultivadas em vasos em casas-de-vegetação e enviadas com raízes nuas. Como este processo é oneroso, eventualmente o doador cobra os custos do receptor, mas assegura o bom estado sanitário da planta.

\section{INTRODUÇÃO DE CULTIVARES PROTEGIDOS}

Os países industrializados possuem legislação que protege o direito do melho- rista ou de patentes para cultivares. Na Europa, existe a "União dos Produtores de Novas Variedades de Plantas" (UPOV) que reconhece apenas o direito do melhorista, sem incluir patente, entretanto, estabelece que nos países onde se reconhece o direito de patentes, o novo cultivar pode ser patenteado, porém, não poderá ser também protegido pelos regulamentos da UPOV. Nos Estados Unidos, o novo cultivar tanto pode ser protegida pela lei do direito do melhorista quanto pela patente.

Segundo o jurista e economista MAST (1987), do Ministério da Justiça da República Federal Alemã, o grande empecilho legal para patentear um cultivar reside no fato de que este não pode ser recriado, como exige a lei de patentes.

Tanto a lei da UPOV quanto a de proteção do direito do melhorista e de patente dos Estados Unidos não impõem restrições ao uso de cultivares protegidos em trabalhos de melhoramento genético, nem em pesquisa biológica. Entretanto, ao introduzir material protegido, dever-se-a assinar um termo de compromisso com o doador, segundo o qual o material não será usado para fins comerciais. Este tipo de compromisso tem sido freqüente para a importação de cultivares de morango, uva, maçã e pêssego da Europa e dos Estados Unidos através do CENARGEN.

No Brasil não se logrou ainda lei de proteção do direito do melhorista, pois o assunto tem recebido enfoque doutrinário-emocional. Precisamos de pesquisas cuidadosas que venham a demonstrar as vantagens ou desvantagens econômicas e sociais dessa lei. As preocupações predominantes no Brasil também existiam na Argentina há anos atrás quando aquele país adotou essa lei, entretanto, segundo técnicos argentinos, tais preocupações não se confirmaram. 
Estudos realizados por GIACOMETTI (1987) mostram que a criação de novas variedades exige grande investimento da EMBRAPA, revelando a necessidade da empresa captar recursos à custa dos novos cultivares a fim de expandir seus programas de melhoramento genético, pois no momento, são as companhias produtoras de sementes que levam as maiores vantagens sobre os novos cultivares criados pelas entidades governamentais e, certamente, a falta de lei que garanta o direito dos melhoristas lhes é de alta conveniência.

\section{CONCLUSÕES E RECOMENDAÇÕES}

1. A introdução ordenada e sistemática de germoplasma constitui estratégia segura e efetiva de se enriquecer a variabilidade genética das plantas cultivadas, indispensável aos programas de melhoramento e pesquisa correlata.

2. Para se garantir o êxito na doação de germoplasma de fontes externas, devese considerar que ocorrem restrições e que solicitações criteriosas envolvendo intercâmbio constituem importante estratégia para o êxito.

3. Inspeções cuidadosas, tratamentos e quarentena de pós-entrada constituem medidas para minimizar os riscos da introdução de pragas e doenças exóticas e para garantir o máximo de segurança.

4. As leis de proteção do direito do melhorista não constituem entraves ao livre intercâmbio de germoplasma.

\section{LITERATURA CITADA}

DAMIANO, C. Tissue Culture in Germplasm Propagation and Exchange. In Guidelines for Seed Exchange and Plant Introduction in Tropical Crops. FAO Plant Production and Protection Paper 76:179-183. 1986.

GIACOMETTI, D.C. Proteção de Cultivares e Direito do Melhorista. In: CONGRESSO BRASILEIRO DE SEMENTES. ABRATES. Gramado, 1987.

GIACOMETTI, D.C. Introdução e Intercâmbio de Germoplasma. In: ENCONTRO SOBRE RECURSOS GENÉTICOS. Eds. Samira Miguel Campos de Araújo e Juan Ayala Osuna. FCAV/UNESP. Jaboticabal. 43-55. 1988.

KHAN, R.P. Plant Quarantine: principles, Methodology and Suggested Approaches. In: Plant Health and Quarentine in International Transfer of Genetic Resources. Eds. William B. Hewitt and Luigi Chiarappa. CRC Press. 25:289-307. 1977.

MAST, H. The relationship Between Plant Variety Protection and Patent Protection in Light of Development in Biotecnology. Plant Variety Protection UPOV Newsletter. 52:14-34. 1986.

VEIGA, R.F.A.; GERMECK, E.B.; FARIA, J.T.; OLIVEIRA, W.R.; NUCCI, T.A.; COELHO, S.M.B.M. O Sistema de Introdução e Quarentena de Plantas do Instituto Agronômico e os Procedimentos Necessários ao Intercâmbio de Germoplasma. Documentos IAC, n.23 (20p.) 1992.

SANGUINO, A. Estação Quarentenária de cana-de-açúcar do Centro de Tecnologia Copersucar. São Paulo. Summa Phytopathologica, v. 14 (81-90). 1988. 